\title{
LA LUCHA CONTRA EL CRIMEN Y EL TRATAMIENTO CORRECCIONAL
}

\section{LA LUCHA CONTRA EL CRIMEN ES UNA FICCION}

En la Tierra aparecieron casi simultáneamente el ser humano y el crimen. Muchos opinan que la historia del hombre y la historia del crimen se confunden. Lo cierto es que el delito ha sido un constante peligro para la convivencia humana y, como es natural, se le ha combatido incesantemeente.

En esta persistente lucha contra el crimen el hombre ha empleado los más diversos medios, particularmente medidas coercitivas. Sin embargo, invariablemente el delito ha sido el gran vencedor. Si bien es verdad que en algunas oportunidades determinados delitos casi desaparecen, otros los reemplazan. Indiscutiblemente el ser humano ha demostrado una completa incapacidad para defenderse de este fenómeno social denominado crimen. Actualmente éste tiende en aumentar cualitativa y cuantitativamente.

Ante esta confirmada realidad es dable de preguntarse ¿a qué se debe esta situación tan trágica?

No la podemos atribuir a un único agente, como es obvio, puesto que sus causas son numerosas. Pero no puede dudarse que ha gravitado en la continuada derrota del hombre las erróneas formas que ha adoptado para combatir el delito.

Al presuntamente más racional de todos los seres se le ha venido imponiendo la más irracional de las medidas: la pena. A la violencia de los infractores se ha respondido con una violencia legalizada. No se ha comprendido aún que es incongruente pretender regular la conducta humana mediante la simple aplicación de las sanciones.

La ley penal señala los actos que no deben realizarse. Cuando se cometen, su autor es castigado, porque ha cometido un delito. El crimen es achacado únicamente a la voluntad humana $y$, por ende, quien ha escogido libremente este camino debe ser penado S:guiéndose una lógica simplista se cree que en la producción del delito sólo actúa la intención del delincuente, sin entenderse que son innumerables los factores etiológicos del crimen. Es asi como la lucha contra la criminalidad ha devenido en una lucha contra el criminal.

Resulta infantil imaginar que podrá desterrarse el delito coriándose la cabeza a un criminal. Podrán ser eliminados millones de delincuentes, pero el delito permanecerá indemne. Ha fracasado igualmente en la lucha contra el crimen la aplicación de la pena privativa de libertad, eje de la actual penología. Esta sanción, de la que tanto se abusa, ha sido estéril para combatir el crimen. Cabe concluir que con la eliminación o el castigo de los delincuentes no desaparecerá o disminuirá la criminalidad. Es así como se ha seguido y se sigue transitando por un equivocado sendero en esta persistente lucha contra el delito.

No negamos que la pena suele intimidar a muchos sujetos y los inhibe de cometer un crimen. Son numerosas las personas que no delinquen porque temen ser penados. A veces la sola presencia de un policía evita la comisión de un delito. Generalmente, estas inhibiciones pasan desapercibidas. Como lo ha señalado el eminente sociólogo mexicano Dr. Lucio Mendieta y Núriez: "Lo que sucede es que mientras la estadística registra el número de los actos delictuosos, no puede registrar las inhibiciones personales y en consecuencia es una estadística unilateral y por lo mismo falsa" (1).

1. Lucio Mendieta y Núñez. "La Ciencia Penitenciaria y la Realidad Social". Sobretiro de la Revista Interamericana de Sociología, Año 2, Vol. II, No 9, Enero-Abril de 1973. México, D. F. (pág. 22). 
Hay que aceptar, sin embargo, que la intimidación producida por la sanción es muy relativa. Un gran número de infractores cree que, de una u otra manera, podrán salvarse de la pena. Desgraciadamente, muchos son los delincuentes que ni siquiera son inculpados por sus crimenes lo que fortalece la creencia que existe.

Por más que se intente negarlo, la lucha contra el crimen ha sido siempre una mera ficción. No se ha luchado contra el delito, sino contra el delincuente, a quien se persigue, se le elimina o sanciona.

El castigo del criminal deja intacto el crimen. Por sí sola, pues, la pena es una medida inocua, con la que no podrá desterrarse el delito. Lo que no quiere decir que no tenga efectos intimidantes en algunos casos.

Lo expresado ha venido a desacreditar el actual sistema penal y penitenciario. Si se anhela conseguir algún éxito en esta persistente lucha contra el crimen, aunque sea limitándolo, habrá que tomar otra senda. Felizmente, se comienza a pensar que el castigo del delincuenie es enteramente infecundo.

\section{NUEVAS FORMULAS PARA COMBATIR EL DELITO}

Durante años el Derecho Penal ha sido representado mediante un símbolo muy elocuente: un hombre enjaulado en una celda. Debe convenirse que es un símbolo vergonzoso. Muchos anhelan hacerlo desaparecer. Esie plausible intento seguramente podrá materializarse en un lejano futuro, puesto que llevará siglos para transformar los criterios que hoy prevalecen.

A marera de saludable reacción se está procurando aplicar nuevas medidas, las que han de ajustarse a la persorialidad de cada infractor. Se camina hacia las medidas irdividualizadas, aunque con una desesperante lentitud. Estas medidas presuponen la individualización judicial y administrativa, tarea difícil de realizar.

En algunas naciones se ha avanzado algo en esta dirección. Refiriéndose a su patria, el Dr. Thorsten Ericksson, Director General de Prisiones de Suecia, dice: "En lugar de un Jurado, el Juez sueco tiene a su lado ura Comisión de expertos que juzgan conjuntamente con él" (2). Incuestionablemente se trata de

2. Thorsten Ericksson. "Problemas Relacionados con la Reforma del Tratamiento de la Delincuencia". Ar- una gran conquista, pero aún insuficlente. En muchas ocasiones los juzgadores se verán limitados por las mismas disposiciones del Código Penal, las que requieren de profundas reformas. Pero éstas han de tropezar con la cerrada oposición de innumerables especialistas en las disciplinas penales, los que generalmente poseen conceptos poco flexibles.

Si se quiere condicionar la medida que se imponga al infractor con las necesidades de la sociedad y del mismo delincuente debe llegarse al arbitrio judicial. Sin embargo, como lo hemos dicho anteriormente: "Este conlleva peligros graves. No queda sino esperar que se produzca una lenta y serena evolución que conduzca a la ansiada solución. Hasta ahora se trata de un tema controvertible, siendo muy delicado tomar partido en favor o en contra de sistemas que ofrecen face'as positivas y negativas, a la vez" (3).

Comprobándose el conocido accionar del péndulo una vez más, la arbitrariedad judicial de antaño tiende a convertirse en arbitrio judicial hoy. Con el arbitrio judicial quizás podría alcanzarse la individualizac:ón judicial de la o las medidas aplicables. Empero, es imperativo reconocer que esta individualización judic'al requiere que los jueces tengan una científica formación y que se hallen asesorados con un personal técnico que integre un equipo. En algunas naciones será posible contar con esta calidad de jueces y con tales equipos técnicos. Pero falta en la mayoría. Por tanto, nos encontramos frente a un distante ideal.

No pequemos de pesimismo, sin embargo, toda vez que se han alcanzado ya algunas conquistas importantes. Por ejemplo, en la actualidad se está reduciendo el valor del delito y, por el contrario, se está otorgando máxima consideración al dellincuente. A éste se le observa y estudia en sus múltiples rasgos con el auxilio de diversas disciplinas científicas, procurándose conocer al criminal. Constituye un efectivo paso hacia la individualización de la medida.

Son numerosas las naciones que ya han hecho importantes conquistas en este terreno. La condena de ejecución condicional o suspensión de la ejecución

chivos de Criminología, Neuro-Psiquiatría y Disciplinas Conexas", Segunda Epoca, Vol. XI, No 44, Octubre-Diciembre de 1963. Quito, Ecuador, (pág. 613).

3. Julio Altmann Smythe. "La Determinación de la Sanción Penal". "Criminalia", Año XXXV, No 10, 31 de Octubre de 1969. México, D. F., (pág. 595). 
de la pena es un logro trascendente. El delincuente es juzgado y condenado, pero no es recluido en una prisión, salvándosele de caer en un ambiente inapropiado. Algunos jueces la aplican aún en casos en que la Ley no lo permite, por estimarla sumamente benéfica. Otra conquista es la anulación de la acción penal. Se suspende la expedición de la sentencia o el mismo juzgamiento. En ocasiones, el infractor ni siquiera comparece ante los tribunales, lográndose el anonimato del delito y del delincuente. Según muchos especialistas este anonimato tiene una singular importancia, puesto que entre mayor sea la ignorancia que se tenga del infractor son mayores las posibilidades de que éste pueda rehabilitarse y hacer una vida social normal.

Es obvio que estas medidas han de sujetarse a determinadas normas. En todo caso el delincuente deberá cumplir con ciertas reglas de conducta y recibir un tratamiento en libertad, bajo una orientación y vigilancia técnica, nunca policial. En determinadas nac'ones tiene intervención la misma colectividad mediante la actividad de agrupaciones que se hallan controladas y dirigidas por organismos de servicio social.

En el campo de la ejecución penal predomina actLalmente la idea de otorgar al penado un tratamiento individualizado con el propósito de reinconporarlo a la comunidad como un elemento útil y respetuoso de la ley penal. Casi todos los regímenes penitenciarios del mundo hoy aceptan plenamente esta tendencia, aunque tan solo teóricamente. Existe todavía un abismo entre la doctrina y la práctica. Como lo ha afirmado Thorsten Ericksson: "En el terreno del tratamiento de la delincuencia. todas las naciones están subdesarrolladas. Incluso países que por circunstancias fortuitas pueden considerarse como bien desarrollados económica y socialmente, han de reconocer que su forma de tratar la delincuencia dista mucho del grado de desarrollo general alcanzado en los demás órdenes" (4). Y agrega: "El tratamiento de la delincuenc.a se halla en todos los países, sin excepción, en una situación de lucha para lograr mejores condiciones y con ello obtener mejores resultados" (5).

Estas aseveraciones de Ericksson deben ser valoradas apropiadamente, pues han sido hechas por un penitenciarista de gran relieve y que conoce bien las

4 y 5. Thorsten Ericksson. Estudio citado., (págs. 609 y 610$)$. condiciones en que se realiza el tratamiento de los delincuentes en prácticamente todos los países del mundo civilizado, habiendo visitado y estudiado las prisiones de Europa, América del Norte, América Latina, Asía y Africa. En 1963 visitó algunas cárceles peruanas.

Actualmente se confiere al tratamiento correccional ura enorme trascendencia en el campo de la prevención de la criminalidad. Pero, como to indica Ericksson, hasta ahora sus resultados han sido muy limitados.

\section{EL. TERMINO "TRATAMIENTO"}

El vocablo "tratamiento" se viene empleando desde hacen ya varios lustros. Se le usa cada vez más freclentemente, habiéndolo prohijado definitivamente el Derecho Penal, la Criminologia, la Ciencia Penitenciaria, el Derecho Penitenciario, etc.

Los certámenes científicos también lo emplean preferentemente. Verbigracia, los congresos quinquenales de las Naciones Unidas denomínanse "congresos sobre prevención del delito y tratamiento del delincuente".

Asimismo han adoptado este vocablo muchas legislaciones de diversas naciones, pudiendo decirse que el término se ha universalizado.

Las disposiciones legales que se refieren a niños y a adolescentes disociales lo emplean generalmente. Así, la ley belga sobre infancia y adolescencia se llama "ley de Tratamiento de Menores".

Hay que reconocer, empero, que el término se ha pedido prestado a la ciencia médica. A fin de poder expresar mejor su significado se le ha agregado al substantivo "tratamiento" el adjetivo "correccional". De esta suerte son muchos autores que hablan del "tratamiento correccional". Personalmente creo que es poco acertado usar este adjetivo, que lleva en si e! concepto de "corrección". Juzgo que con el tratamiento no se busca la corrección del infractor y, mucho menos, su transformación. Se pretende únicamente su no reincidencia, esto es, su readaptación jurídico-social.

\section{OBJETIVOS DEL TRATAMIENTO}

Muchos tratadistas hiperbolizan los objetivos del tratamiento al concederle exageradas finalidades. No faltan los que suponen que la meta del tratamiento es la 
"cura social" del sujeto. Pecan igualmente de una excesiva pretensión los que creen que con él se busca la "integral" readaptación social del individuo, dándole una significación distinta al término "integral". Otros juzgan que intenta transformar al delincuente en sus características sociales, psíquicas y éticas, lo que es sumamente ambicioso.

Conviene señalar que las "Reglas Mínimas" de las Naciones Unidas nunca usan los vocablos "reincorporación" y ni siquiera "readaptación" cuando se refieren a los objetivos del tratamiento.

Comulgo con el pensamiento del distinguido penitenciarista y criminólogo Prof. Manuel López-Rey, quien ha dicho que el tratamiento debe perseguir únicamente la readaptación jurídico-social del infractor, para que no reincida. Se trata de un enfoque realista. Asi considerado, quizás el ámbito se reduzca, aunque posee alcances de singular trascendencia, como me to ha expresado en muchas ocasiones. Si el tratamiento logra que el criminal desarrolle sus actividades sin quebrantar la ley penal y convive con sus semejantes útil y correctamente al regresar a la comunidad se habrán alcanzado los resultados que se anhelan.

El Prof. López-Rey posee una concepción muy suya acerca de las finalidades del tratamiento y de su aplicación: "Debe tenerse presente que el dictamen y el tratamiento persiguen una finalidad socio-política y no meramente clínica, científica o asistencial. Lo de socio-politico se refiere a la función penal del Estado ejercida deficiente o malamente por la Administración penitenciaria, que no puede ignorarse. Al presente, esa función se intenta justificar mediante la readaptación según muchos, la protección según otros y la prevenc:ón e intimidación según algunos. Aislada o combinadamente tales fines son socio-políticos" (6).

Según nuestro criterio, los objetivos básicos del tratamiento son:

1.-Que el infractor desee sinceramente respetar la ley penal;

2.-Que se halle capacitado para poder cumplir con este propósito;

3.--Que posea aptitud para adaptarse nuevamente a su hogar, a sus labores y, en general, a su medio,

6. Manuel López Rey. "Presupuestos de la Orientación Profesional Penitenciaria". Talleres de Gráfica Americana. Caracas, Venezuela., (1972)., (pág. 58). considerándose que tendrá que vivir en una comunidad normal; y

4.-Que se encuentre habilitado para poder subsistir mediante un trabajo lícito, esto es, honesto.

\section{OBLIGACION DEL ESTADO DE INTENTAR LA RECUPERACION DEL INFRACTOR}

En la actualidad, generalmente al delincuente se le priva de su libertad. Pero ¿para qué? Incuestionablemente no es para castigarlo, sino para recuperarlo, a fin de que regrese a la sociedad como un individuo que respete la ley penal y no constituya una carga social. E.l estado y la Sociedad tienen el deber irrefragable de procurar se cumpla este objetivo fundamental.

Si se le priva a un hombre de su libertad es obvio que es para realizar una efectiva defensa social. Por tanto, debe intentarse readaptarlo jurídica y socialmente mediante procedimientos bien concebidos. Hoy día a este procedimiento se le llama tratamiento.

EI Papa Pío XII enseñó que era necesario colocar al centro del sistema penal no al delito, sino al delincuente, considerado como persona y como miembro de la Sociedad. Y Quintiliano Saldaña, ya en 1905, agregó a la conocída fórmula "no hay delitos sino delincuentes" otra de muy honda significación: "no hay delincuentes, sino hombres".

El infractor no es un enie abstracto, sino un ser humano, con defectos, cualidades, anomalias, inteligencia, tendencias, ansias de mejoras, flaquezas, etc., etc. $\mathrm{Si}$ se parte de esta concepción será factible encontrar procedimientos que permitan la recuperación social del sujeto. Pero como premisa debe dejar de ser el Derecho Penal un mero formulismo jurídico. Hay que llegar a su reforma, efectiva y real.

\section{LA DIFICIL TAREA DEL TRATAMIENTO}

Actualmente se juzga que sólo excepcionalmente existe la "fatalidad criminal", siendo posible atemperar la proclividad al delito de una persona si es sometida a un procedimiento apropiado, de carácter individualizado. El tratamiento de los infractores se ha originado de esta idea.

La individualización presupone observar al criminal, estudiarlo, conocerlo, efectuar el diagnóstico y el pronóstico así como la programación del tratamiento, cla- 
sificarlo y separarlo en cárceles diversificadas. Pero debe tenerse presente que el delincuente integra un solo todo, una unidad, por lo que su personalidad no puede ni debe ser desarticulada. Por tanto, emplear métodos similares a los usados por la química analítica constituiría un absurdo. Además, debe considerarse de que estas características son interdependientes, intimamente enlazadas, influyéndose unas a otras. Son, pues, inseparables.

Por otro lado, debe pensarse que los caracteres de cada criminal son innumerables y que varian incesantemen'e. El individuo de ayer no es el de hoy y éste seguramente no será el de mañana. Finalmente, que los factores etiológicos del delito cometido son complejos, numerosos $y$, generalmente, mal conocidos. $Y$ algo esencial: son irrepetibles, esto es, no pueden reproducirse artificialmente.

Debe considerarse, asimismo, que tratándose de un tratamiento individualizado los medios que se empleen han de variar en uno u otro caso. Podrán usarse medios psicológicos, psiquiátricos, sociológicos, quirúrgicos, pedagógicos, laborales, etc., etc., los que podrán ser aplicados en forma simultánea o no. A veces solamente deberán emplearse algunos de estos medios y no los otros.

Resulta, consiguientemente, casi imposible señalar con precisión la forma que deberá adoptar el tratamiento y el tiempo que habrá de durar. $Y$ que este tratamiento deberá ser objeto de continuas revaluaciones $y$, por ende, de cambios.

La tarea de otorgar a un delincuente un correcto tratamiento es, pues, tarea sumamente ardua e insegura.

Agréguese que siempre se tropezará con la escasez de los apropiados medios materiales y, particularmente, dificilmente podrá contarse con suficiente personal capacitado.

La eficacia del tratamiento será siempre incierta, debatible y nebulosa tomándose en cuenta lo que se deja expuesto.

\section{EL TRATAMIENTO DE GRUPO}

El tratamiento siempre debe ser individualizado. Pero éste puede adoptar dos fórmulas: "individual" $y$ "de grupo". Cada uno posee un específico radio de acción, por lo que ninguno reemplaza o desaloja al otro.
El tratamiento de grupo, denominado igualmente "colectivo", se oiorga a un reducido conjunto de infractores que ostenten características similares. Es provechoso su otorgamiento a determinadas categorías de delincuentes. Su empleo se ha extendido mucho en los últimos años, especialmente porque presenta algunas ventajas, que son las siguientes:

A) Se aprovechan mejor al siempre reducido personal especializado y a los medios disponibles;

B) Se utiliza la dinámica del mismo grupo;

C) Los consejos y planieamientos de los individuos que integran el grupo son más fácilmente aceptados, disminuyendo la desconfianza y el rechazo; y

D) Se produce una benéfica influencia reciproca entre las personas que forman el grupo.

Se recomienda que la intervención de los técnicos aparentemente parezca mliy limitada; jamás debe exagerársela. Hay que dar la impresión de que los consejos y planieamiento surgen espontáneamente del grupo y que la orientación e iniciativas de los funcionarios apenas sean notados, no obstante su continuado ofrecimiento.

Es obvio que los resultados que se obtengan dependerán de la capacidad y tino de los especialistas, los que dében actuar con suma cautela para no despertar resistencias entre los delincuentes que reciben tratamiento. Nurica será suficiente relevar las dificultades con las que se tropiezan para auxiliar a sujetos que ya han exhibido lendencias disociales, siempre recelosos y con cierta impermeabilidad psíquica debido al cúmulo de problemas insolutos que exhiben.

\section{METODOS DE TRATAMIENTO}

Generalmente se suelen distinguir únicamente dos métodos: 1.-El institucional, otorgado a los internos de un establecimiento penal; y 2.-El no institucional o tratamiento en libertad, que se dispensa a los infractores en la comunidad. Incuestionablemente, esta clasificación es incompleta.

Muchos autores distinguen una extensa variedad de mótodos de tratamiento, pecando de exageración.

Creemos que pueden ser clasificados en cuatro métodos. Es cierto que no comprenden todos, pero se incluyen los más importantes.

Las características más saltantes de estos métodos son las siguientes: 
A) Método Institucional.-Es el que se otorga a los iniernos de instituciones penales, ya sean éstas cerradas, semi-abiertas o abiertas. Varía en cada caso, por tralarse de tratamientos individualizados;

B) Método Semi-Institucional.-Se confiere, a la vez, en una institución y fuera de ella. Puede adoptar dos fisonomías:

1.-Método Semi-Institucional propiamente dicho.Se da a aquellos penados que salen del establecimiento, por ejemplo, para trabajar regularmente en talleres y fábricas, que se hallan en la comunidad cercana. Reciben, por tanto, tratamiento en la institución y en la comunidad; y

2.-Método Discontinuo.-Se proporciona a condenados que cumplen la pena privativa de libertad en períodos fraccionados, como aquéllos que se internan los fines de semana y permanecen en la comunidad los demás días;

C) Método Trans-Institucional.-Es el que se confiere a los delincuentes que gozan de libertad condicional, por lo que ya han cumplido parte de la condena en una institución penal. Han recibido, pues, tratamiento iristitucional. Al regresar a la sociedad se les somete a traiamiento no institucional; $y$

D) Método no institucional absoluto.-El tratamiento se otorga solamente en libertad, como, por ejemplo, a los infractores que han sido beneficiados con la suspensión condicional de la sentencia o con otras medidas simi'ares, como "probation", etc. No reciben jamás un tratamiento institucional.

Se ha afirmado que la prisión es un ambiente que debe evitarse, de ser factible. Es por tal motivo que actualmente se prefiere el tratamiento no institucional siempre y cuando esté acompañado por un efectivo auxilio y orientación técnica.

\section{EL TRATAMIENTO EN LAS "REGLAS MINIMAS" DE LAS NACIONES UNIDAS}

Estas se Iimitan al tratamiento institucional. Sin embargo, bien podrian servir de norma aplicable en todos los anteriormente métodos indicados.

A continuación se comentarán algunas sintéticamente:

La Regla $58^{\circ}$ dice textualmente que "el fin y la justificación de las penas y medidas privativas de libertad son, en definitiva, proteger a la sociedad contra el crimen" (7). Con la aplicación de estas penas y medidas, pues, se aspira evitar que el infractor reincida.

La Regla $65^{\circ}$ se refiere especificamente al tratamiento irstitucional. Indica: "El tratamiento de los condenados a una pena o medida privativa de libertad debe tener por objeto, en tanto que la duración de la condena lo permita, inculcarles la voluntad de vivir conforme a la ley, mantenerse con el producto de su trabajo y crear en ellos el respeto de si mismos y desarrollar el sentido de responsabilidad" (8). Con el tratamiento se aspira la reincorporación del delincuente a la sociedad como un elemento útil y no peligroso, una vez vuelto a la comunidad.

Como puede verse, las opiniones personales dadas a conocer en este trabajo concuerdan con los básicos objetivos señalados en las "Reglas Mínimas" de las Naciones Unidas. Lo que se anhela es que el infractor, al regresar a la comunidad, pueda llevar una existencia respetuosa a la ley penal, provechosa y que no sea una gravosa carga para la sociedad. Lo esencial es que no reincida.

Aun en aquellos países en que las "Reglas Mínimas" se han aplicado correctamente no se han logrado estos objetivos plenamente. En Suecia, por ejemplo, que es una de las naciones precursoras del tratamiento y que acusa efectivos progresos en este campo, superándose a lo que disponen estas "Reglas Mínimas", conforme con la autorizada opinión del Dr. Thorsten Ericksson, todavía está luchando pora poder obtener mejor en resultados.

\section{EL TRATAMIENTO EN LAS "NORMAS MINIMAS" MEXICANAS}

La Ley que estableció las Normas Mínimas sobre Readaptación Social de Sentenciados fue publicada en el Diario Oficial el 19 de Mayo de 1971 con vigencia en el Distrito y Territorios Federales de la República Mexicana únicamente. Sin embargo, aplicándose su Art. $3^{\circ}$, se están aplicando estas Normas en varias entidades federativas mediante convenios celebrados en-

7. "Primer Congreso de las Naciones Unidas sobre Prevención del Delito y Tratamiento del Delincuente". Ginebra, 22 de Agosto - 3 de Setiembre de 1955. Informe de la Secretaría. Versión en Castellano. Naciones Unidas, Nueva York. A/CONF/6/1, Mayo de 1956. No de venta: 1956. IV. 4., (pág. 77).

8. Informe citado., (pág. 78). 
tre el Gobierno Federal y algunos Gobiernos de estos Estados.

Las Normas Mexicanas se han inspirado en las "Reglas Mínimas" de las Naciones Unidas, debiéndose reconocer que en algunos aspectos las superan, lo que debe ser objeto de satisfacción para los autores del Proyecto, entre los que destaca el Dr. Sergio García Ramírez, uno de los más capacitados penitenciaristas de América Latina. La posición vanguardista de esta Norma seguramente se debe a su influencia.

Son varias las normas que se refieren al tratamiento. En. seguida se comentarán sumariamente:

El Art. 6? dice textualmente: "El tratamiento será individualizado, con aportación de las diversas ciencias y disciplinas pertinentes para la reincorporación social del sujeto, consideradas sus circunstancias personales". Y agrega: "Para la mejor individualización del tratamiento $y$ tomando en cuenta las condiciones de cada medio y las posibilidades presupuestales, se clasificará a los reos en instituciones especializadas, entre las que podrán figurar establecimientos de seguridad máxima, media y mínima, colonias y campamentos penales, hospitales psiquiátricos y para infecciosos e instituciones abiertas" (9). El tratamiento individualizado, pues, se otorga, en lo posible, en cárceles diversificadas, sin que se señalen todas sus diversas caracierísticas. Por otro lado, en forma realista, se indica que deberá contemplarse las posibilidades presupuestales.

Determina su Art. 7ㅇ: "El régimen penitenciario tendrá carácter progresivo y técnico y constará, por lo menos, de períodos de estudio y diagnóstico y de tratamiento, dividido esto último en fases de tratamiento en clasificación y de tratamiento preliberación. El tratamiento se fundará en los resultados de los estudios de personalidad que se practiquen al reo, los que deberán ser actualizados periódicamente". "Se procurará iniciar el estudio de personalidad del interno desde que quede sujeto a proceso, en cuyo caso se turnará copia de dicho estudio a la autoridad jurisdiccional de la que aquél dependa" (10). Dos aspectos son dignos de aplaudirse: a) Que el tratamiento ha de merecer ser periódicamente actualizado; y b) Que el estudio de la personalidad del interno comenzará desde que ingresa a un establecimiento penal como procesado y que copia de las conclusiones de dicho estudio será enviado a los jueces que han de señalar la pena o medida, lo que es esencial.
Textualmente su Art. 8 o señala: "El tratamiento preliberacional podrá comprender: I.-Información y orientación especiales y discusión con el interno y sus familiares de los aspectos personales y prácticos de su vida en libertad; II.-Métodos colectivos; III.-Concesión de mayor libertad dentro del establecimiento; IV.-Traslado a la institución abierta; y V.--Permisos de salida de fin de semana o diaria con reclusión nocturna, o bien de salida en días hábiles con reclusión de fin de semana" (11). Se establece, pues, el tratamiento preliberación, adoptando modalidades bastante completas. Por de pronto, se procura la readaptación del penado a su hogar y al medio en donde vivirá una vez que abandone la prisión. Establece, asimismo, el tratamiento de grupo o colectivo. Igualmente, algunas medidas preparatorias acertadas se haIlan en los incisos III, IV y V del articulo.

Estas Normas latinoamericanas enfocan el tratamiento institucional con visión científica, buscándose la readaptación jurídico-social de los infractores.

El Art. 9० de la Ley crea en cada reclusorio un Consejo Técnico, con funciones bastante amplias. Se haIla integrado por el Director del Establecimiento, o por el funcionario que le sustituya en sus faltas, que lo presidirá, y por los miembros de superior jerarquia del personal directivo, administrativo, técnico y de custodia, y en todo caso formarán parte de él un médico y un maestro normalista. Este Consejo Técnico ya ha demostrado su eficiencia en el Centro Penitenciario del Estado de México, establecido por su primer Director, Dr. Sergio Garcia Ramirez, y que continúa funcionando, con las mejoras que la experiencia ha indicado, con su actual Director, el eminente penitenciarista Lic. Antonio Sánchez Galindo, su primer Subdirector.

Juzgamos imprescindible terminar estos breves comentarios de las "Normas Mínimas" mexicanas - comentario que no ha llegado a contemplar otros diversos aspectos que acerca del tratamiento determinan estas normas, conceptuando que este trabajo debe terer una limitada extensión- algunos conceptos expresados por el Dr. Sergio Garcia Ramirez, principal autor del Proyecto de Ley, quien dice: "Un verdadero

9, 10 y 11. "Ley que establece las Normas Mínimas sobre readaptación social de sentenciados". Sergio García Ramírez. "La Reforma Penal de 1971". Ediciones Botas. México, D. F., 1971., (Págs. 95, 96, 97, 98 y 99). 
centro de tratamiento, cual debe ser cada cárcel, al parejo que unidad de docencia y de investigación científica, requiere la dotación humana y física indispensable para el tratamiento interdisciplinario. Aquí, la función ruclear será cumplida por el organismo técnico criminológico. Sobre esto existen, en el plano internacional, versiones $y$ denominaciones diferentes. En algunos casos se acepta la orientación sociológica, al paso que en otros se hace lo propio con la dirección antropológica. El organismo pluripersonal asume a veces la estructura y las tareas de un simple tribunal de condicla, mientras que en otras circunstancias se desarroila hasta rematar en verdadera entidad criminológica y aborda, resueltamente, todos los temas del tratamiento. En rigor, este organismo dedicado al diagnóstico, al prorióstico y a la conducción de la terapia individual, forma parte en las piezas clave del nuevo régimen penitenciario" (12).

\section{EL TRATAMIENTO EN LA LEY PERUANA}

Con fecha 15 de Abril de 1969 fue expedido el Decreto-Ley No 17581, denominado "Unidad de Normas para Ejecución de Sentencias Condenatorias". Unicamenie por tratarse de una disposición peruana se le comentará brevemente, puesto que ha sido inoperante, hasta ahora. Debe puntualizarse que parece que este dispositivo legal será derogado para expedirse otro más moderno, según las declaraciones que se han efectuado en el Ministerio del Interior, del cual dependen las prisiones.

Los Arts. $3^{\circ}$ y $4{ }^{\circ}$ de este Decreto-Ley indican las firalidades de la ejecución de la pena privativa de libertad, siendo la fundamental la de lograr la readaptación del condenado, para que, una vez salido de la prisión, se convierta en un elemento útil y de provecho para la comunidad.

"La administración carcelaria está obligada a clasificar al recluso como parte de su tratamiento readaptativo", determina el Art. 10, y el inc. b) de su Art. 11 dice: "La clasificación tendrá por objetivos básicos... determinar el tratamiento individualizado del recluso, previo estudio de su personalidad y medio circundante, a fin de establecer la consiguiente afec-

12. Sergio García Ramírez. "La Reforma Penal de 1971”. Ediciones Botas. México, D. F., 1971., (págs. 64 y 65). tación al establecimiento carcelario apropiado" (13). Está demás puntualizar que la administración carcelaria no ha cumplido con esta obligación que le señala el Art. 10\%, que no se da tratamiento alguno a los internos y, mucho menos, se les envía a establecimientos diversificados, por cuanto aún no se ha suprimido el irracional y anticientífico sistema geográficoadministrativo, incumpliéndose, asimismo, lo que dispone el Art. 149 del Decreto-Ley.

Otra disposición que no se ha respetado es el Art. 13ㅇ, el que ordena “디 Poder Ejecutivo creará los organismos técnicos necesarios a fin de lograr el tratamiento individualizado del condenado" (14).

Es obvio, por tanto, que igualmente se incumple lo dispuesto por el Art. 200: "En el período de observación el organismo técnico respectivo realizará: a) El estudio del condenado, que comprenderá su examen médico, psicológico y del medio ambiente que lo circundaba antes de cometer el hecho delictuoso a efecto de formular el diagnóstico y pronóstico criminológico. b) Clasificará al condenado según sus posibilidades de adaptación a la vida social. c) Indicará el establecimiento o sección de establecimiento a que debe ser destinado. d) Fijará el tratamiento concreto a que debe ser sometido el condenado y e) Determinará el tiempo mínimo para comprobar los resultados del tratamiento fijado y procederá a su actualización, si fuera necesario" (15).

Los arts. $76^{\circ}$ y $77^{\circ}$ disponen que el Servicio Social Criminológico colaborará en el tratamiento de los iniernos. Debe recordarse que funciona el Servicio Social Criminológico desde 1947, aunque solamente en Lima y Callao, puesto que no se le ha prestado apoyo para su desarrollo y extensión.

Lamentablemente, tampoco se ha dado cumplimiento a lo que ordena el Art. 820: "El Poder Ejecutivo dictará los reglamentos Generales y Especiales para la aplicación de la presente Ley" (16).

\section{INUTILIDAD DEL TRATAMIENTO SOBRE ALGUNOS INFRACTORES}

En ocasiones el tratamiento es absolutamente estéril. Por motivos diversos el tratamiento que se otorga a cierta categorias de infractores es inútil.

13 y 14. Copia preparada por el Ministerio del Interior, Dirección General de Establecimientos Penales, del Decreto-Ley No 17581

15 y 16. Copias citadas. 
El Prof. Manuel López-Rey y Arrojo se refirió a las diversas clases de infractores que no responden a tratamiento alguno por razones particulares en el VIII Congreso Internacional de Defensa Social, Paris, 1971. Insiste en sus ideas en la obra ya citada "Prespuestos de la Orientación Profesional Penitenciaria", publicada en 1972. Ciñéndonos a sus más importantes conclusiones, indicaremos en seguida algunos casos en que el tratamiento de los delincuentes resulta infructuoso:

A) Los delincuentes condenados a penas cortas de prisión, puesto que materialmente falta tiempo para poder otorgárseles apropiado y suficiente tratamiento institucional;

B) Muchos individuos que permanecen en calidad de procesados durante largos períodos. Cuando son condenados finalmente tampoco queda tiempo para que reciban el tratamiento que requieren; generalmente en América Latina los procesos penales duran un tiempo exagerado;

C) Delincuentes politicos, o que enmascaran sus delitos alegando motivaciones políticas -que rechazan todo tratamiento, siendo lógico que si no se cuenta con una mínima colaboración del delincuente todo intento de tratamiento resultará vano. Para algunos inconformes o rebeldes los delitos que cometen son actos plausibles, convenientes y necesarios para que se logre la desaparición de un orden social, económico, politico, cultural y ético que odian. Estiman que debe ser destruido, por lo que usan medios que las leyes perales consideran delictuosos. "Readaptación" significa "domesticación" a una situación injusta y que no aceptan, justamente por considerarla arbitraria; y

D) Algunos criminales que presentan condiciones psicológicas o de otra índole que los hacen impermeables a toda readaptación jurídico-social. Son refractarios a todo tratamiento. Es natural que cualquier tratamiento devendrá en un fracaso.

Aburidan los infractores pertenecientes a las anotadas categorias. Las estadisticas y la experiencia evidencian que los básicos objetivos del tratamiento rara vez se alcanzan. Por ejemplo, en los Estados Unidos de Norte América la reincidencia llega a más del $60 \%$. En Francia las estadísticas indican que ésta se acerca al $50 \%$. Resultados similares se constatan en otros muchos paises que poseen estadísticas bien con- troladas. Por otro lado, debe señalarse que dichas estadísticas no reflejan la realidad, por cuanto muchos casos de reincidencia no son captados y, por ende, no son recogidas por éstas.

Son desalentadores estos resultados, los que se deben a muy distintos factores. Uno de estos es la prisión misma.

Finalmente, cabe apuntar que existen delincuentes que solamente requieren de un corto tratamiento, otorgado en libertad. Han cometido un delito, grave - no, presionados por motivos fortuitos. Son verdaderas víctimas de imprevistas circunstancias, a las que todos estamos expuestos.

\section{EL TRATAMIENTO FRECUENTEMENTE NO BASTA}

Hoy nadie duda de que algunos delincuentes alcanzan su readaptación socio-jurídica mediante la aplicación de un tratamiento correcto. Pero, asimismo, se acepta que otros jamás se readaptan. Permanecen, pues, desadaptados por más esfuerzos que cumplan los técnicos. Quizás estos últimos formen la mayoría. Debe modestamente reconocerse que los resultados del tratamiento son pobres. No podemos ilusionarnos mucho al respecto.

Aunque se obtenga la readaptación en algunos casos permanece la duda si junto al tratamiento no han intervenido otros factores más decisivos. Es una incógnita difícil de resolver.

Lo expresado no indica que se minifique la importancia de un científico tratamiento, puesto que las posib:lidades de poderse readaptar jurídico-socialmente a un infractor no desaparecen totalmente. Aún más. Se trata de una acción muy promisora, por to que debe pugnarse en ella, perfeccionándola. Es de imaginar que los escasos resultados obtenidos hasta ahora se deban a la incapacidad del personal penitenciario, a una escasa dotación física, a los métodos empleados, al ambiente en el que se otorga, etc.

Sin embargo, es innegable que se ha confiado demasiado en el tratamiento, olvidándose la realidad que reflejan las estadísticas y la diaria experiencia. Esta debe ser registrada, reconociéndose, con pesadumbre, que han sido mínimos los resultados del tratamiento.

Hay que convencer y convencerse de que el tratamiento es absolutamente insuficiente para combatir el 
crimen. Mientras que la prevención especial, representada por el tratamiento, no se perfeccione y se le complete con una amplia y efectiva prevención general, el ser humano continuará siendo derrotado por el delito. Debemos confesar honestamente y con sinceridad que se continúa transitando por el engañoso sendero de siempre en ésta ya larga lucha contra el crimen.

La prevención general ofrece enormes posibilidades. Esto significa terminar con las situaciones que inferiorizan al hombre. Si se modifican las condiciones políticas, sociales, económicas, culturales, éticas, etc. que actualmente prevalecen quizás sea factible combatir al crimen con alguna efectividad. Empero, se trata de una tarea larga y polifacética, la que habrá de tomar muchos siglos.

Los organismos estatales de prevención poseen un radio de acción bastante limitado $y$, por ende, sus posibilidades son sumamente escasas. Ya lo he expresado anteriormente: "El cambio de las estructuras socioeconómicas no son de su directa competencia. En todo caso es quimérico pensar que podrá controlar los fenómenos nacidos del desarrollo, del incontrolable aumento de la población, de la general incultura, de la difusión de las enfermedades mentales, etc., etc." (17).

Lo que dejamos expresado no puede ser discutido. Entonces ¿qué debemos hacer para alcanzar algún éxito?

En el Boletín Informativo del Centro Criminológico Internacional se dice: "Desde hace ya varios decenios, las Escuelas criminológicas de Roma y de Harvard han claramente demostrado, sobre la base de una larga experiencia clínica (Di Tullio) y experimental (Sheldon y Eleonor Glueck), que es posible identificar desde su niñez a los menores predispuestos a un futuro comportamiento antisocial y criminal" (18). En varios pai-

17. Julio Altmann Smythe. "Las Normas Mínimas Mexicanas, un plan de política penitenciaria”. Revista Mexicana de Prevención y Readaptación Social", Vol., I, No 5, Setiembre-Octubre de 1972. México, D. F., (pág. $14)$.

18. Boletín Informativo del Centro Criminológico Internacional "Hacia una nueva Política Criminal". Tibergraf-Piazzale V. Bottego, 51, Roma, 1972, (pág. 7). ses se han obtenido excelentes resultados siguiéndose tales técnicas. Naturalmente, debe buscarse la identificación a una temprana edad del menor, aplicándosele un inmediato tratamiento.

Por tanto, es muy promisora una acción que identifique tempranamente a los niños proclives a conductas irregulares, disociales y delictuosas, para otorgárseles un pronto y científico tratamiento. Sería de recomendar que las cuantiosas sumas que se gastan, a veces infructuosamente, en el tratamiento de los delincuentes adultos, se invirtieran en esta prevención tan llena de posibilidades, cada vez en mayor proporción. Es sabido que en numerosos paises se despilfarran los dineros fiscales para encarcelar solamente a los delincuentes, a los que no se dispensa ningún tratamiento.

El esciarecido Prof. Franco Ferracuti está obteniendo magníficos resultados en el Centro Penitenciario Criminológico de Rebibbia, Roma. Anteriormente, es te mismo criminólogo, Catedrático de la Universidad de Roma, conjuntamente con el Prof. Simón Dinitz, de la Universidad Estatal de Ohio, han demostrado que puede advertirse con una certeza que alcanza el $100 \%$ de los casos, esta proclividad. Ha demostrado, asimismo, que la inadapción escolar anuncia el futuro comportamiento antisocial o criminal de los menores. Estos largos, serios y rigurosos experimentos fueron realizados en Puerto Rico. Estas conclusiones están apoyadas por una labor cientifica de muchos años, por lo que no pueden discutirse.

Se encuentra ampliamente probado de que los criminales más peligrosos y particularmente los reincicidentes crónicos acusan en.el historial de su niñez una notable irregularidad, la que ulteriormente ha dado lugar a explosiones delictivas. Estas verificaciones nos hacen creer que si, cuando riños, se hubiese identificado su predisposición a un comportamiento antisocial y criminal y si hubiesen recibido un tratamiento científico a temprana edad, es posible que no llegarían a convertirse en delincuentes, evitándose incalculables perjuicios.

Es, pues, sumamente promisora esta acción preventiva. Quizás si estuviésemos encaminando mejor la persistente lucha nue el hombre está librando contra el crimen, hasta anora tan infructuosamente. Por lo menos es un sendero que hay que explorar. 